\title{
Adolescent diet and risk of breast cancer
}

\author{
A Lindsay Frazier ${ }^{1,2}$, Catherine Tomeo Ryan², Helaine Rockett ${ }^{2}$, Walter C Willett ${ }^{2,3,4}$ and \\ Graham A Colditz 2,4
}

\author{
${ }^{1}$ Division of Pediatric Oncology, Dana-Farber Cancer Institute, Harvard Medical School, Boston, Massachusetts, USA \\ ${ }^{2}$ Channing Laboratory, Department of Medicine, Brigham and Women's Hospital, Harvard Medical School, Boston, Massachusetts, USA \\ ${ }^{3}$ Department of Nutrition, Harvard School of Public Health, Boston, Massachusetts, USA \\ ${ }^{4}$ Department of Epidemiology, Harvard School of Public Health, Boston, Massachusetts, USA \\ Corresponding author: A Lindsay Frazier (e-mail: lindsay.frazier@channing.harvard.edu)
}

Received: 18 Jun 2002 Revisions requested: 10 Jul 2002 Revisions received: 4 Dec 2002 Accepted: 21 Jan 2003 Published: 21 Feb 2003

Breast Cancer Res 2003, 5:R59-R64 (DOI 10.1186/bcr583)

(C) 2003 Frazier et al., licensee BioMed Central Ltd (Print ISSN 1465-5411; Online ISSN 1465-542X). This is an Open Access article: verbatim copying and redistribution of this article are permitted in all media for any purpose, provided this notice is preserved along with the article's original URL.

\section{Abstract}

Background: Early life exposures, including diet, have been implicated in the etiology of breast cancer.

Methods: A nested case-control study was conducted among participants in the Nurses' Health Study who completed a 24-item questionnaire about diet during high school. There were 843 eligible cases diagnosed between onset of study (1976) and before the return of the high school diet questionnaire (1986), who were matched 10:1 with controls on the basis of age.
Results: Women who had, during adolescence, a higher consumption of eggs, vegetable fat and fiber had a lower risk of breast cancer, whereas risk of breast cancer was increased among women who consumed more butter.

Conclusions: A possible association of elements of adolescent diet with risk of breast cancer is reported, but the findings require confirmation in prospective study.

Keywords: adolescence, breast cancer, diet

\section{Introduction}

The evidence that adolescent diet may affect the risk of breast cancer derives from several lines of evidence [1]. Rates of breast cancer among Asian immigrants to the United States do not approach those of US white women until the second or third generation, suggesting that exposures during childhood and adolescence are important in establishing a higher risk of breast cancer [2,3]. Norwegian women who were adolescents during World War II, when average caloric intake decreased by $22 \%$, have a reduced incidence of breast cancer, suggesting that energy restriction might affect risk [4]. Similarly, in animal models, energy restriction in the peripubertal period inhibits mammary tissue proliferation and reduces the subsequent risk of mammary tumors $[5,6]$. Exposure of rats to carcinogens before first pregnancy increases the incidence of mammary tumors compared with exposure after first pregnancy [7]. After differentiation of the mammary gland at the time of first full-term pregnancy of the rat, the rate of cell division decreases and length of the cell cycle increases, allowing more time for DNA repair [8]. This biologic phenomenon might explain the apparent vulnerability of the adolescent breast tissue to carcinogenic exposures. Among atomic bomb survivors and women exposed to ionizing radiation as part of their treatment for Hodgkin's disease, the risk of breast cancer increases with younger age at exposure [9].

Although this analysis was principally an exploratory analysis to guide prospective studies, the authors had previously proposed that certain elements of adolescent diet might be protective against future risk of breast cancer [10]. For instance, we and others have proposed that fiber might be protective by lowering endogenous estrogen levels and that folate might be protective owing to its role in DNA methylation. 


\section{Methods \\ Study population}

This study was conducted among the participants of the Nurses' Health Study, a prospective cohort of 121,700 women who have completed biennial questionnaires on medical events and lifestyle factors since the initiation of the study in 1976, when the women were 30-55 years of age [11]. The study has been approved by the institutional review board at the Brigham and Women's Hospital, Boston.

\section{High school food-frequency questionnaire}

In 1986, when participants were 40-65 years of age, they completed a 24-item food-frequency questionnaire (FFQ) about diet between the ages of 12 and 18 years. The FFO was designed to include foods that account for major sources of fat, antioxidant vitamins, and carotenoids. For each food item on the FFQ, a unit or portion size was specified. Subjects were asked how often, on average, they had consumed the specified amount of each item. Nine possible responses were provided ranging from 'never' to 'six or more per day'.

Nutrient intakes were computed for each subject by assigning a weight proportional to the frequency of use of each food, multiplying this weighting by the nutrient value for the specified portion size, and summing the contributions of all foods. The nutrient database used in this study was derived from the US Department of Agriculture's handbook [12] with additional information from McCance and Widdowson [13] and also from data obtained from food manufacturers. The database incorporates research on the historical trends in the enrichment of the food supply, such as the addition of vitamin $D$ to milk (beginning in about 1932) and vitamin A to margarine (in about 1941). For vitamin A, women born before 1942 were assigned 'unenriched' values; women born after 1942 were assigned 'enriched' values. The questionnaire has been shown to be highly reproducible and not significantly correlated with current diet as an adult $(r=0.25)$ [14].

Participants who had completed the high school diet assessment section of the 1986 follow-up questionnaire and who also had reported current diet in 1980 were eligible for the study. Incident cases of breast cancer, confirmed by medical record review, diagnosed after the report of current diet in 1980 and before the return of the 1986 questionnaire on which high school diet was reported, were eligible for inclusion in the study ( $n=1313)$. The analysis included both in situ and invasive cases of breast cancer. One hundred and thirty-six cases died before the mailing of the 1986 questionnaire, 69 cases did not return the 1986 questionnaire, and 175 cases did not fill out the high school diet section of analysis if the total calories reported on high school diet were implausible, i.e. less than 500 or greater than 4500 $(n=16)$, if the reported age at menarche was greater than 21 years $(n=9)$, or if they had previously been diagnosed with cancer other than breast cancer $(n=65)$. The final case pool $(n=843)$ included $64 \%$ of the cases diagnosed between 1980 and 1986. Included cases had a later age at menarche, were more likely to be premenopausal, and were more likely to report a family history of breast cancer than cases excluded from the analysis (data not shown). Controls were matched to cases by month and year of birth in a 10:1 ratio. The exclusion criteria for controls were the same as for cases.

\section{Statistical analysis}

Controls were assigned the date of diagnosis of their matched case. The risk factor status of both cases and controls was updated from the questionnaire most recently completed before date of diagnosis (controls were assigned the date of diagnosis of their matched case). Risk factors that were updated included menopausal status, family history, diagnosis of benign breast disease, and postmenopausal hormone use. All tests of significance were two-sided. Differences in risk factor status between cases and controls were tested with $\chi^{2}$ or $t$-tests.

Foods were analyzed as continuous variables based on the number of servings per day. Nutrients were analyzed using quintiles of nutrient intake, according to the distribution in the control population. Multiple logistic regression was used to estimate relative risks as odds ratios (and 95\% confidence intervals [Cls]) while controlling simultaneously for potentially confounding variables. Trends across quintiles were tested with the use of the logistic model. Relative risks were estimated as odds ratios (and 95\% Cls) while controlling simultaneously for potentially confounding variables. Trends across quintiles were tested with the use of the logistic model. Relative risks (RR) were calculated by comparing the highest and lowest quintiles of nutrient intake $\left(Q_{5}\right.$ versus $\left.Q_{1}\right)$. Multivariate models included age at diagnosis, family history of breast cancer in mother or sister, diagnosis of benign breast disease (BBD), age at menarche (in quintiles), body mass index at age 18 (in deciles), adult height (in quartiles), reproductive history (categorical), and vitamin $A$ intake (continuous) in 1980 [15]. Current vitamin A intake was included in the model because we have previously shown in this cohort of women that lower intake of vitamin $A$ is positively associated with an increased risk of breast cancer. Reproductive history was represented by dummy variables, indicating whether the subject had children, and, if so, the number of children (one, two, or more than two children) and the age at which the first child was born (before age 24, between ages 25 and 29 inclusive, or age 30 or older). 


\section{Results}

Breast cancer cases had later age at first birth, lower parity, increased adult height, and higher incidence of $\mathrm{BBD}$, and were more likely than controls to have a family history of breast cancer. Cases also reported lower vitamin A intake and higher alcohol intake in 1980 than did controls (data not shown).

Increased consumption of eggs was associated with decreased risk of breast cancer $(R R=0.82$ per increase of one serving per day; 95\% $\mathrm{Cl}$ 0.67-0.99) (Table 1). Consumption of butter was positively associated with increased risk of breast cancer $(R R=1.06 ; 95 \% \mathrm{Cl}$ 1.00-1.13). RR values for individual foods were generally similar for premenopausal and postmenopausal women. Foods were grouped according to type (fruits, vegetables, dairy, red meat, chicken, fish), but none of the groupings was significantly related to risk of breast cancer.

Nutrient analysis, controlling for other established risk factors, showed that greater consumption of vegetable fat (RR $\left[\mathrm{Q}_{5}\right]=0.85, P$ [trend $]=0.05$ ) and dietary fiber (RR $\left[\mathrm{Q}_{5}\right]=0.78 ; P$ [trend] $\left.=0.09\right)$ were related to a reduced risk of breast cancer (Table 2). No other associations between nutrient intake and risk of breast cancer were observed. Inclusion versus exclusion of adult height, which might be on the causal pathway between adolescent diet and adult health, did not substantially alter the results reported.

\section{Discussion}

In this nested case-control study, the relation of adolescent diet to risk of breast cancer was evaluated among participants in the Nurses' Health Study who had completed a 24-item FFQ about diet during high school. Increased consumption of eggs was inversely associated with risk of breast cancer. Eggs are rich sources of essential amino acids, minerals and vitamins. For instance, one egg contains $11.5 \%$ of the recommended daily allowance for folate and $6.5 \%$ of that for vitamin D [16]. Conversely, increased consumption of butter was associated with a slight increase in risk. Neither animal fat, total fat, nor unsaturated fat was associated with increased risk on nutrient analysis; however, another nutrient in butter might confer increased risk, or the consumption of butter might be a proxy for another risk factor.

When specific nutrients were examined, increased consumption of both vegetable fat and dietary fiber was associated with a decreased risk of breast cancer. Fiber might affect the risk of breast cancer by decreasing estrogen levels; fiber binds estrogen excreted into the gastrointestinal tract and reduces enterohepatic circulation [17,18]. In addition, higher dietary fiber intake has been associated with higher plasma levels of sex-hormone-binding globulin, which can reduce the bioavailability of estrogens [19]. The poten-
Table 1

\begin{tabular}{|c|c|c|}
\hline Food (serving) & $\begin{array}{l}\text { Median servings } \\
\text { per day }\end{array}$ & $\begin{array}{l}\mathrm{RR}(95 \% \mathrm{Cl}) \\
\text { for } 1 \text { serving per day }\end{array}$ \\
\hline Milk, skimmed (1 cup) & 0 & $1.03(0.88-1.21)$ \\
\hline Milk, whole (1 cup) & 1.00 & $1.01(0.95-1.07)$ \\
\hline Milkshake (1) & 0.07 & $1.06(0.70-1.60)$ \\
\hline Ice cream ( $1 / 2$ cup) & 0.14 & $0.94(0.71-1.23)$ \\
\hline Cheese (1 slice) & 0.14 & $0.91(0.71-1.16)$ \\
\hline Margarine (1 pat) & 0.43 & $0.96(0.89-1.03)$ \\
\hline Butter (1 pat) & 0.80 & $1.06(1.00-1.13)$ \\
\hline Apple (1) & 0.43 & $1.00(0.83-1.20)$ \\
\hline Orange juice (1 glass) & 0.43 & $0.97(0.82-1.14)$ \\
\hline Cabbage (1/2 cup) & 0.14 & $1.00(0.64-1.57)$ \\
\hline Broccoli (1/2 cup) & 0.07 & $0.74(0.39-1.41)$ \\
\hline Carrots ( $1 / 2$ cup) & 0.14 & $1.15(0.91-1.46)$ \\
\hline Spinach (1/2 cup) & 0.07 & $1.18(0.72-1.93)$ \\
\hline Egg (1) & 0.43 & $0.82(0.67-0.99)$ \\
\hline Hot dog (1) & 0.14 & $0.82(0.52-1.31)$ \\
\hline Beef (1 serving) & 0.43 & $1.03(0.88-1.20)$ \\
\hline Fish (3-5 ounces) & 0.14 & $0.94(0.64-1.37)$ \\
\hline Bread (1 slice) & 2.50 & $0.98(0.92-1.04)$ \\
\hline Rice (1 cup) & 0.07 & $0.85(0.62-1.17)$ \\
\hline Potato (1 cup) & 0.80 & $0.93(0.80-1.08)$ \\
\hline French fries ( 4 ounces) & 0.07 & $1.04(0.72-1.49)$ \\
\hline Cold cereal (1 cup) & 0.43 & $0.99(0.83-1.19)$ \\
\hline Cookies (2) & 0.80 & $0.96(0.89-1.04)$ \\
\hline Multivitamin & 0 & $1.04(0.84-1.28)$ \\
\hline
\end{tabular}

Relative risks (RR) are adjusted for age at diagnosis, age at menarche, menopausal status, family history, benign breast disease, adult height, parity/age at first birth, postmenopausal hormone use, body mass index at age 18, alcohol intake in 1980, and vitamin A intake, excluding supplements, in 1980 among 843 cases of breast cancer age matched 10:1 with controls. $\mathrm{Cl}$, confidence interval.

tial mechanism of a protective effect of vegetable fat is more speculative: vegetable fat is a composite of multiple forms of fatty acids, some of which have been proposed to increase risk (such as $\mathrm{C}_{18: 2} \mathrm{n}-6$ ) whereas other specific fatty acids have been proposed to decrease risk (such as $C_{18: 1}$, the primary fatty acid in olive oil) [20]. More detail on the type and composition of the vegetable oil used is necessary to pursue this relation with greater precision.

Several limitations to the study exist. First, the validity of diet data recalled from 22 to 47 years in the past is 
Table 2

\begin{tabular}{|c|c|c|c|c|c|c|c|}
\hline Nutrient & Parameter & $\mathrm{Q}_{1}$ & $\mathrm{Q}_{2}$ & $\mathrm{Q}_{3}$ & $\mathrm{Q}_{4}$ & $\mathrm{Q}_{5}$ & $P$ for trend \\
\hline \multirow[t]{2}{*}{ Protein (g/day) } & Median intake & 34.9 & 50.1 & 61.3 & 73.3 & 93.5 & \\
\hline & Multivariate RR & 1.0 & 0.92 & 0.98 & 0.88 & 0.88 & 0.27 \\
\hline \multirow[t]{2}{*}{ Animal fat (g/day) } & Median intake & 25.5 & 39.7 & 51.2 & 64.2 & 84.7 & \\
\hline & Multivariate RR & 1.0 & 0.98 & 0.95 & 0.94 & 1.01 & 0.96 \\
\hline \multirow[t]{2}{*}{ Vegetable fat (g/day) } & Median intake & 5.4 & 9.3 & 12.2 & 17.8 & 28.3 & \\
\hline & Multivariate RR & 1.0 & 1.12 & 1.13 & 0.96 & 0.85 & 0.05 \\
\hline \multirow[t]{2}{*}{ Monounsaturated fat (g/day) } & Median intake & 13.3 & 19.4 & 24.4 & 29.9 & 39.8 & \\
\hline & Multivariate RR & 1.0 & 1.01 & 0.90 & 0.95 & 0.89 & 0.28 \\
\hline \multirow[t]{2}{*}{ Saturated fat (g/day) } & Median intake & 14.5 & 22.2 & 29.0 & 36.5 & 48.4 & \\
\hline & Multivariate RR & 1.0 & 0.92 & 0.94 & 0.86 & 0.98 & 0.82 \\
\hline \multirow[t]{2}{*}{ Total fat (g/day) } & Median intake & 35.5 & 52.3 & 66.2 & 81.5 & 107.5 & \\
\hline & Multivariate RR & 1.0 & 1.11 & 0.86 & 1.0 & 0.92 & 0.32 \\
\hline \multirow[t]{2}{*}{ Folate $(\mu \mathrm{g} /$ day $)$} & Median intake & 81.9 & 117 & 151 & 181 & 238 & \\
\hline & Multivariate RR & 1.0 & 0.92 & 1.01 & 0.89 & 0.86 & 0.21 \\
\hline \multirow[t]{2}{*}{ Vitamin A (IU/day) } & Median intake & 2063 & 3457 & 4901 & 7311 & 11,437 & \\
\hline & Multivariate RR & 1.0 & 1.01 & 0.95 & 1.13 & 1.02 & 0.63 \\
\hline \multirow[t]{2}{*}{ Retinol (IU/day) } & Median intake & 612 & 1001 & 1378 & 1814 & 5542 & \\
\hline & Multivariate RR & 1.0 & 1.06 & 0.89 & 1.02 & 1.05 & 0.59 \\
\hline \multirow[t]{2}{*}{ Carotenoid (IU/day) } & Median intake & 1053 & 2030 & 3214 & 4832 & 9253 & \\
\hline & Multivariate RR & 1.0 & 1.14 & 1.08 & 1.16 & 1.10 & 0.65 \\
\hline \multirow[t]{2}{*}{ Vitamin C (mg/day) } & Median intake & 24.6 & 40.3 & 62.1 & 91.2 & 121 & \\
\hline & Multivariate RR & 1.0 & 0.88 & 1.01 & 0.90 & 0.95 & 0.77 \\
\hline \multirow[t]{2}{*}{ Vitamin D (IU/day) } & Median intake & 107 & 186 & 308 & 385 & 691 & \\
\hline & Multivariate RR & 1.0 & 0.86 & 0.98 & 0.99 & 0.96 & 0.84 \\
\hline \multirow[t]{2}{*}{ Vitamin E (IU/day) } & Median intake & 2.20 & 3.30 & 4.10 & 5.20 & 8.10 & \\
\hline & Multivariate RR & 1.0 & 1.07 & 1.04 & 0.98 & 0.87 & 0.18 \\
\hline \multirow[t]{2}{*}{ Dietary fiber (g/day) } & Median intake & 5.6 & 7.5 & 9.10 & 11.0 & 14.3 & \\
\hline & Multivariate RR & 1.0 & 0.84 & 1.01 & 0.89 & 0.78 & 0.09 \\
\hline
\end{tabular}

Results are from multivariate analyses adjusted for age at diagnosis, age at menarche, menopausal status, family history, benign breast disease, adult height, parity/age at first birth, postmenopausal hormone use, body mass index at age 18, alcohol intake in 1980, and vitamin A intake, excluding supplements, in 1980 among 843 cases of breast cancer age matched 10:1 with controls.

unknown. Although we have shown that this recall is reproducible and is not highly correlated with current diet [14], we can only infer validity. Potischman et al. [21] have shown that there is a strong degree of concordance between the report of mother and the report of daughter about foods consumed during this age period, although others have shown that recall of diet from the distant past is imprecise [22]. However, in the absence of dietary data actually collected during adolescence, recall of high ships between diet during adolescence and the risk of breast cancer.

Second, the 24-item FFQ is too short for complete assessment of total energy intake or specific nutrients. For instance, the intake of folate calculated from high school FFO is much lower than the range seen in adult women [23]; median intake group in the top quintile of intake during high school was only $238 \mu \mathrm{g}$ per day. Given the restricted list of foods from which the nutrients were 
derived, more emphasis should be placed on the analysis of foods than of nutrients when interpreting these data.

A third limitation of the current study is the possibility of recall bias because high school diet history was obtained after diagnosis of breast cancer. The most prevalent, although apparently incorrect, dietary hypothesis among the general population in 1986 was the notion that increased fat consumption significantly increased risk. Nevertheless, in this study the lack of association of fat intake suggests that recall bias was probably not a major factor. However, the brevity of this questionnaire might not have permitted complete recording of all sources of fat.

A further limitation is the possibility of survivor bias. Only cases alive in 1986 who had completed the high school diet portion of the questionnaire were included in the analysis. If adolescent diet in any way increases the risk of mortality from breast cancer, women with these adverse dietary patterns would not be included in analysis, and the relation would be distorted. Finally, there remains the possibility of residual confounding by unmeasured factors, for instance socioeconomic status during childhood and its impact on dietary composition.

Four other studies of the relation between childhood diet and breast cancer have been reported previously. Pryor et al. [24] conducted a case-control study of adolescent diet and breast cancer in Utah. Recall of diet was assessed by a modification of the Block questionnaire, selecting for foods higher in fat and fiber. No data were presented on the foods themselves; only possible relations between fat and fiber, stratified by menopausal status, were reported. Higher intake of fat from dairy sources was associated with a decreased risk of breast cancer for both premenopausal and postmenopausal women. This conclusion contrasts with the finding of our study in which a higher intake of butter was associated with a small increase in risk. A higher intake of fiber decreased risk in premenopausal women, whereas a higher intake of fiber was associated with an increased risk of breast cancer in postmenopausal women, analogous to a finding of the present study.

Hislop et al. [22] conducted a case-control study in British Columbia among 846 incident cases of breast cancer between 1980 and 1982. Women were asked to recall their dietary intake of 31 foods during early childhood (up to age 13 years). In premenopausal women, consumption of meat with visible fat during childhood was associated with an increased risk of breast cancer (RR ['three or more times per week' compared with 'less than once per month'] $=2.69 ; 95 \% \mathrm{Cl} 1.26-5.80)$ Consumption of vegetable oils was associated with a reduced risk in premenopausal women $(\mathrm{RR}=0.48 ; 95 \% \mathrm{Cl} 0.25-0.89$ ). We also observed an inverse relationship between the intake of vegetable fat and the risk of breast cancer.
Potischman et al. [21] conducted a case-control study among 1647 cases who had been diagnosed with breast cancer at less than 45 years of age. Participants were asked during a telephone interview to quantify their intake of 29 foods at ages 12-13 years. The mothers of the participants were also asked to recall their daughter's intake of foods at ages 12-13 years. The response of each mother was highly correlated with the daughter's report. The authors reported that increased consumption of highfat meats was associated with an increased risk of breast cancer, whereas increased consumption of fruits and vegetables was associated with a non-significant but consistent decrease in risk of breast cancer.

\section{Conclusion}

The present study revealed that increased consumption of eggs was associated with a decreased risk of breast cancer, whereas increased consumption of butter was associated with a slight increase in risk. In addition, increased intake of vegetable oils and dietary fiber seemed to be inversely related to risk of breast cancer. Future studies of the relation between adolescent diet and risk of breast cancer are warranted and should include a more complete assessment of diet.

\section{Competing interests}

None declared.

\section{Acknowledgements}

We thank Jennifer Angell and Carol Leighton for their expert assistance. This study was supported by Public Health Service Grant CA 50385 (National Cancer Institute). ALF was supported by KO7CA62252 (National Cancer Institute). WCW is supported by Special Institutional Grant-15 from the American Cancer Society.

\section{References}

1. Hunter DJ, Willett WC: Diet, body size, and breast cancer. Epidemiol Rev 1993, 15:110-132.

2. Buell $P$ : Changing incidence of breast cancer in JapaneseAmerican women. J Natl Cancer Inst 1973, 51:1479-1483.

3. Ziegler RG, Hoover RN, Pike MC, Hildesheim A, Nomura AM, West DW, Wu-Williams AH, Kolonel LN, Horn-Ross PL, Rosenthal JF: Migration patterns and breast cancer risk in AsianAmerican women. J Natl Cancer Inst 1993, 85:1819-1827.

4. Tretli S, Gaard M: Lifestyle changes during adolescence and risk of breast cancer: an ecologic study of the effect of World War II in Norway. Cancer Causes Control 1996, 7:507-512.

5. Engelman RW, Day NK, Good RA: Calorie intake during mammary development influences cancer risk: lasting inhibition of $\mathrm{C} 3 \mathrm{H} / \mathrm{HeOu}$ mammary tumorigenesis by peripubertal calorie restriction. Cancer Res 1994, 54:5724-5730.

6. Arts CJ, Govers CA, van den Berg $\mathrm{H}$, Thijssen $\mathrm{JH}$ : Effects of wheat bran and energy restriction on onset of puberty, cell proliferation and development of mammary tissue in female rats. Acta Endocrinol 1992, 126:451-459.

7. Russo J, Tay LK, Russo IH: Differentiation of the mammary gland and susceptibility to carcinogenesis. Breast Cancer Res Treat 1982, 2:5-73.

8. Russo J, Russo $\mathrm{HH}$ : Biological and molecular bases of mammary carcinogenesis. Lab Invest 1987, 57:112-137.

9. Tokunaga M, Land CE, Tokuoka S, Nishimori I, Soda M, Akiba S: Incidence of female breast cancer among atomic bomb survivors, 1950-1985. Radiat Res 1994, 138:209-223.

10. Colditz GA, Frazier AL: Models of breast cancer show that risk is set by events of early life: prevention efforts must shift focus. Cancer Epidemiol Biomarkers Prev 1995, 4:567-571. 
11. Colditz GA: The Nurses' Health Study: a cohort of US women followed since 1976. J Am Med Womens Assoc 1995, 50:4044.

12. US Department of Agriculture: Composition of foods - raw, processed, and prepared, 1963-1988. Washington, DC: Department of Agriculture, Government Printing Office; 1989.

13. Holland G, Welch AA, Unwin ID, Buss DH, Paul AA, Dat S: The Composition of Foods. Cambridge, UK: Royal Society of Chemistry and Ministry of Agriculture, Fisheries and Food; 1991.

14. Frazier AL, Willett WC, Colditz GA: Reproducibility of recall of adolescent diet: Nurses' Health Study (United States). Cancer Causes Control 1995, 6:499-506.

15. Hunter D: A prospective study of the intake of vitamins C, E, and A and the risk of breast cancer. N Engl J Med 1993, 329:234-240.

16. Vorster HH, Beynen AC, Berger GM, Venter CS: Dietary cholesterol-the role of eggs in the prudent diet. S Afr Med J 1995, 85:253-256.

17. Arts CJ, de Bie AT, van den Berg H, van 't Veer P, Bunnik GS, Thijssen $\mathrm{JH}$ : Influence of wheat bran on NMU-induced mammary tumor development, plasma estrogen levels and estrogen excretion in female rats. J Steroid Biochem Mol Biol 1991, 39:193-202.

18. Arts CJ, Govers CA, van den Berg H, Wolters MG, van Leeuwen $\mathrm{P}$, Thijssen $\mathrm{JH}$ : In vitro binding of estrogens by dietary fiber and the in vivo apparent digestibility tested in pigs. $J$ Steroid Biochem Mol Biol 1991, 38:621-628.

19. Goldin BR, Woods MN, Spiegelman DL, Longcope C, MorrillLaBrode A, Dwyer JT, Gualtieri LJ, Hertzmark E, Gorbach SL: The effect of dietary fat and fiber on serum estrogen concentrations in premenopausal women under controlled dietary conditions. Cancer 1994, 74(Suppl):1125-1131.

20. Willett WC: Specific fatty acids and risks of breast and prostate cancer: dietary intake. $A m$ J Clin Nutr 1997, 66(Suppl):1557S-1563S.

21. Potischman N, Weiss HA, Swanson CA, Coates RJ, Gammon MD, Malone KE, Brogan D, Stanford JL, Hoover RN, Brinton LA: Diet during adolescence and risk of breast cancer among young women. J Natl Cancer Inst 1998, 90:226-233.

22. Friedenreich CM, Slimani N, Riboli E: Measurement of past diet: review of previous and proposed methods. Epidemiol Rev 1992, 14:177-196.

23. Willett WC, Sampson L, Stampfer MJ, Rosner B, Bain C, Witschi $\mathrm{J}$, Hennekens $\mathrm{CH}$, Speizer FE: Reproducibility and validity of a semiquantitative food frequency questionnaire. $A m \mathrm{~J} E p i$ demiol 1985, 122:51-65.

24. Pryor M, Slattery ML, Robison LM, Egger M: Adolescent diet and breast cancer in Utah. Cancer Res 1989, 49:2161-2167.

25. Hislop TG, Coldman AJ, Elwood JM, Brauer G, Kan L: Childhood and recent eating patterns and risk of breast cancer. Cancer Detect Prev 1986, 9:47-58.

\section{Correspondence}

A Lindsay Frazier MD MSc, Channing Laboratory, 181 Longwood Avenue, Boston, MA 02115, USA. Tel: +1 617525 2042; fax: +1 617 525 2008; e-mail: lindsay.frazier@channing.harvard.edu 